BMJ Open Sport \& Exercise Medicine

\section{Inpatient and emergency department costs from sports injuries among youth aged 5-18 years}

To cite: Ryan JL, Pracht EE, Orban BL. Inpatient and emergency department costs from sports injuries among youth aged $5-18$ years. BMJ Open Sport \& Exercise Medicine 2019;5:e00491. doi:10.1136/ bmjsem-2018-000491

Accepted 21 February 2019
Check for updates

\section{(C) Author(s) (or their} employer(s)) 2019. Re-use permitted under CC BY-NC. No commercial re-use. See rights and permissions. Published by BMJ

${ }^{1}$ Health Sciences and Administration, University of West Florida College of Science Engineering and Health, Pensacola, Florida, USA ${ }^{2}$ Health Policy and Management, University of South Florida, Tampa, Florida, USA

Correspondence to Dr Jessica L Ryan; jryan@uwf.edu

\section{ABSTRACT}

Objective To analyse the financial costs from sports injuries among inpatients and emergency department (ED) patients aged 5-18 with a focus on Medicaid patients. Methods Fixed-effects linear regression was used to assess the association of patient factors with cost of injury from sports. Florida Agency for Health Care Administration data from 2010 to 2014 were used, which included all inpatient and ED patients aged 5-18 years who had a sports injury.

Results Over 5 years, sports injuries in Florida youth cost \$24 million for inpatient care and \$87 million for ED care. Youth averaged $\$ 6039$ for an inpatient visit and $\$ 439$ for an ED visit in costs from sports injuries. Sports injuries for Medicaid-insured youth cost $\$ 10.8$ million for inpatient visits and $\$ 44.2$ million for ED visits.

Conclusion Older athletes and males consistently have higher healthcare costs from sports. Baseball, basketball, bike riding, American football, roller-skating/skateboarding and soccer are sports with high costs for both $E D$ patients and inpatients and would benefit from prevention programmes. Injuries from non-contact sport participants are few but can have high costs. These athletes could benefit from prevention programmes as well.

\section{INTRODUCTION}

The cost of sports injuries in youth is substantial $^{1-6}$; from 2000 to 2003, hospitalisations from youth sports injuries in the USA annually cost between \$113 and \$133 million. ${ }^{7}$ Identified research gaps include the scope of costs and differences between populations. ${ }^{37-9}$

The purpose of this research was twofold. The first objective was to estimate the medical costs from sports injuries among inpatient and emergency department (ED) youth patients in Florida. The second objective was to analyse patient factors associated with cost to aid in assessing the magnitude of the problem and who is most vulnerable.

In 2012, Finch argued that one of the key reasons public health prevention programmes have not been implemented at a policy level is lack of data about the size and scope of the problem-specifically information on which groups are at risk, effective and cost-effective
What are the new findings

Scope of sports injury costs for youth in Florida

Differences in healthcare costs of sports injuries between populations.

Differences in healthcare costs of sports injuries between sports.

How it might impact on clinical findings in the near future

Injury prevention programmes for athletes may need to be targeted differently.

- Non-contact sport participants may need specific injury prevention and recovery programmes.

prevention programmes, medical treatments, cost measurements, and policy implications. ${ }^{10}$ Finch listed three questions to determine if an issue needs to be put on a government public health agenda: (1) Is the problem large enough? (2) Which of the community members are most vulnerable? (3) Why should the government be concerned? ${ }^{10}$ Population-level injury prevention strategies have not been applied to sport activities, resulting in current research citing a critical need to prioritise sports injury prevention in children under 15 years of age. ${ }^{151112}$

An estimated 30-45 million youths in the USA play recreational and competitive sports. ${ }^{13}$ Sports are encouraged for youth to promote physical activity and instil values such as teamwork and good sportsmanship, and many enjoy sports while gaining satisfaction and confidence from participating. However, some youth will be injured while participating in sports, with some seeking ED care or requiring hospitalisation, and a portion of these will be covered by Medicaid. In Florida, an estimated 1.7 million youth have Medicaid insurance. ${ }^{14}$

Approximately 3.5 million youth annually receive medical treatment for a sports injury, ${ }^{15}$ and sports injuries account for $30 \%$ 
of youth ED visits related to consumer products in the USA. ${ }^{4}$ Previous research found that males have a higher risk of injury in team sports and females have a higher injury risk in individual sports. ${ }^{16}$ In addition, white youth are at higher risk of sports injury. ${ }^{17}$ Almost half (49\%) of paediatric hospitalisations from sports injury were 15-18 years of age, $85 \%$ were male and $54 \%$ had a fracture. ${ }^{7}$ Sports injuries typically have mild injury severity scores and low mortality rates; however, they can still lead to hospitalisation, disability, long-term health impact and high healthcare costs. ${ }^{11819}$ In addition, injuries acquired as youth may have a lifelong impact on a person's physical activity level and health. ${ }^{60}$

\section{METHODS}

The Florida Agency for Health Care Administration (AHCA) ED and inpatient data sets from 2010 to 2014 were used in this analysis. The data sets are mutually exclusive, so ED patients discharged into the inpatient unit of the same hospital are not included in the ED data. The data include demographic variables, up to 30 diagnoses, and external cause of injury codes (E-code) for patients who had an ED visit or admission to an acute care hospital. The AHCA also releases annual hospital financial data, which include ownership status, location and financial information. The hospital factors were merged with the patient data for each year so the model could control for differences in the 123 Florida hospitals.

Inpatient and ED patients between the ages of 5 and 18 who had a sports-related E-code were included in the analysis. Patients were categorised into age groups approximating various school divisions: elementary school included ages 5-10, middle school included ages 11-13 and high school included ages 14-18. Other patient demographics such as gender, race, ethnicity and payer type were used in this analysis. Payers are the insurance companies who pay for patients' healthcare. This study included the three main types of insurance for youth in the USA, which are commercial (private insurance companies), Medicaid (state-run insurance for youth in low-income families) and uninsured (the patient is responsible to pay their healthcare costs). Payer types and status are included in the model to capture potential differences in utilisation related to comprehensiveness of coverage and, by extension, the out-of-pocket price to the patient. For example, the uninsured may seek less care as a way to avoid paying full price at the time of delivery. Conversely, commercially insured patients may request more services as their out-of-pocket price at the time of delivery is reduced to copayment arrangements. The International Classification of Diseases, Ninth Revision, Clinical Modification (ICD-9-CM) Injury Severity Score (ICISS) method was used to measure injury severity. ICISS ranges from 0 to 1 , with unity indicating $100 \%$ survival and 0 implying $100 \%$ mortality. The lower the ICISS, the more severe the injury or combination of injuries. The severity variable used was ICISS multiplied by
100 in order for the model estimates to be more easily interpreted.

Patients who had an injury from a sport were identified using the following E-code fields: E006.x (individual sports), E007.x (team sports), E008.x (other sports), E886.0 (fall from sports), E917.0 (struck in sports) and E917.5 (struck and fall in sports). These include all ICD-9-CM codes that had 'sports' in the description. The inpatient data included 4658 observations and the ED data included 234754 observations. Observations were omitted from the model analysis if they did not include an E-code for a specific, named sport, for example patients who were injured with an E-code of a general nature such as 'struck in sports' or 'other activity involving other sports'. Observations were also omitted from the model analysis if the patient did not seek treatment for one of the injuries defined in the Barell Injury Diagnosis Matrix. The Barell Injury Diagnosis Matrix is a commonly used tool in injury epidemiology that uses ICD-9-CM codes to classify injury by body region and nature of injury. Examples from those omitted observations included youth patients who were principally diagnosed with an unspecified episodic mood disorder or other cellulitis or abscess. One patient whose costs were 12 times higher than the average was omitted as a cost outlier. For the final analysis, the model included 2303 inpatient observations.

The sports E-codes were categorised according to the American Academy of Paediatrics' Committee on Sports Medicine and Fitness (2001). ${ }^{21}$ The categories were full contact or collision sports, limited contact sports, and non-contact sports. The full contact sports group included observations with E-codes of E007.0 (American football), E007.2 (rugby), E007.4 (lacrosse/field hockey), E007.5 (soccer), E007.6 (basketball), E008.0 (boxing), E008.1 (wrestling) and E008.4 (martial arts). The limited contact group included E006.0 (roller-skating/skateboarding), E006.1 (horseback riding), E006.4 (bike riding), E007.1 (flag football), E007.3 (baseball), E007.7 (volleyball), E008.2 (racquet/hand sports) and E008.3 (Frisbee). The non-contact sports group included observations with E-codes of E006.2 (golf), E006.3 (bowling), E006.5 (jump roping) and E006.6 (non-running track and field).

The principal diagnosis code of the patients was used to create the nature of injury categories according to the Barell Injury Diagnosis Matrix. Injuries were categorised using the matrix into fractures of the skull, neck and trunk; other fractures; sprains and strains; internal; open wound; amputations; blood vessels; contusion/superficial; crush; burns; nerves; and unspecified according to the principal diagnosis code of the patient. ${ }^{22}$ The reference group for the analysis included sprains and strains and contusion/superficial injuries. Burns, blood vessels, nerves, amputation and crush each accounted for well under $1 \%$ of the total observations. Therefore, these were added to the unspecified injury observations and this variable was called 'other injuries'. 
Table 1 Demographics of financial costs for inpatient youth, 2010-2014

\begin{tabular}{|c|c|c|c|}
\hline \multirow[b]{2}{*}{ Age } & \multirow[t]{2}{*}{ Count } & \multicolumn{2}{|c|}{ Inpatient: 2014 dollars } \\
\hline & & Average (\$) & Sum (\$) \\
\hline Elementary school & 639 & 4634 & 2845546 \\
\hline Middle school & 1043 & 5457 & 5598898 \\
\hline High school & 2479 & 6641 & 16111103 \\
\hline \multicolumn{4}{|l|}{ Gender } \\
\hline Female & 612 & 5738 & 3402635 \\
\hline Male & 4046 & 6091 & 21152913 \\
\hline \multicolumn{4}{|l|}{ Race } \\
\hline Black & 1142 & 6571 & 7418243 \\
\hline Other & 471 & 5855 & 2687512 \\
\hline White & 3045 & 5831 & 14449792 \\
\hline \multicolumn{4}{|l|}{ Ethnicity } \\
\hline Hispanic & 747 & 5733 & 4167879 \\
\hline Non-Hispanic & 3911 & 6106 & 20387668 \\
\hline \multicolumn{4}{|l|}{ Principal payer } \\
\hline Medicaid & 1767 & 6252 & 10821525 \\
\hline Uninsured & 242 & 5433 & 1282299 \\
\hline Commercial & 2649 & 5932 & 12451724 \\
\hline All inpatients & 4658 & 6039 & 24555547 \\
\hline
\end{tabular}

The inpatient cost model was analysed using a linear regression with residence county fixed effects, meaning the variables were analysed within each county to control for differences between counties. The dependent variable was cost of the hospital visit. This was calculated from the total charges of the visit as reported in the AHCA. The total charges were multiplied by each hospital's annual weighted cost-to-charge ratio to estimate the actual patient care cost. Cost-to-charge ratios are the reported total costs divided by the total revenue of each cost centre. Cost-to-charge ratios were calculated for each hospital for each year. The cost centre ratios were then combined for an annual weighted overall hospital cost-to-charge ratio. The costs found were then adjusted for inflation to 2014 dollars using the producer price indexes for hospital inpatient care and hospital outpatient care accordingly. The distribution of costs was highly skewed; therefore, the cost variable was transformed using the natural logarithm. Microsoft Excel 2016, Microsoft Access 2016 and SAS V.9.4 software were used in this analysis.

\section{RESULTS}

Sports injuries in youth aged 5-18 cost \$24.55 million for inpatient care and $\$ 87$ million for ED care in the state from 2010 to 2014. The cost of these sports injuries is broken down by demographics in table 1 for inpatient visits and table 2 for ED visits. The average cost of an inpatient visit was $\$ 6039$. Sports injuries for Medicaid-insured youth cost $\$ 10.8$ million for inpatient visits. The average cost of an ED visit for an injured youth from sport was
Table 2 Demographics of financial costs for ED youth, 2010-2014

\begin{tabular}{|c|c|c|c|}
\hline \multirow[b]{2}{*}{ Age } & \multirow[t]{2}{*}{ Count } & \multicolumn{2}{|c|}{ ED: 2014 dollars } \\
\hline & & $\begin{array}{l}\text { Average } \\
(\$)\end{array}$ & Sum (\$) \\
\hline Elementary school & 43586 & 342 & 12724455 \\
\hline Middle school & 68059 & 483 & 27959448 \\
\hline High school & 122747 & 449 & 46399569 \\
\hline \multicolumn{4}{|l|}{ Gender } \\
\hline Female & 51786 & 327 & 14076603 \\
\hline Male & 182968 & 470 & 73006869 \\
\hline \multicolumn{4}{|l|}{ Race } \\
\hline Black & 64849 & 582 & 33270537 \\
\hline Other & 25540 & 312 & 6707468 \\
\hline White & 144365 & 394 & 47105467 \\
\hline \multicolumn{4}{|l|}{ Ethnicity } \\
\hline Hispanic & 48195 & 253 & 10420486 \\
\hline Non-Hispanic & 186559 & 488 & 76662986 \\
\hline \multicolumn{4}{|l|}{ Principal payer } \\
\hline Medicaid & 121379 & 422 & 44236556 \\
\hline Uninsured & 22251 & 671 & 12406006 \\
\hline Commercial & 91124 & 406 & 30440910 \\
\hline All ED patients & 234754 & 439 & 87083472 \\
\hline
\end{tabular}

ED, emergency department.

\$439. Sports injuries for Medicaid-insured youth cost $\$ 44.2$ million for ED visits.

Tables 3 and 4 show the costs for inpatient and ED visits by sport E-code. For inpatient visits, the average cost per sport per visit ranged from $\$ 3231$ (jump roping) to $\$ 28$ 366 (Frisbee). However, the Frisbee average was affected by the outlier observation. The next highest average cost was golf ( $\$ 14693)$, followed by volleyball ( $\$ 12370)$. American football had the highest total costs with a sum of almost \$4.9 million.

For ED visits, the average ED cost per sport ranged from $\$ 189$ to $\$ 655$. Patients who had an E-code of 'struck in sports' had the highest average cost with $\$ 655$ per injury, followed by golf (\$628), fall from sports $(\$ 599)$ and horseback riding (\$444). Correspondingly, 'struck in sports' also had the highest total cost of injury with $\$ 55.3$ million over 5 years. American football had the second highest total ED costs with a sum of $\$ 11.5$ million, followed by basketball with a sum of $\$ 8$ million.

Table 5 provides the cost regression model of inpatient youth injured by sport, which had an overall model $F$ value of 29 with a $p$ value of $<0.0001$, meaning at least one of the predictor variables was significantly associated with cost. The $r^{2}$ for the model was 0.24 . Nested models of each group of predictor variables were tested (demographics, sport, admission, injury type, injury severity and hospital factors) and all were found to be statistically significant. Younger age groups were associated with lower cost; 
Table 3 Financial costs for inpatient youth by sports E-code, 2010-2014

\begin{tabular}{|c|c|c|c|}
\hline & Count & Inpatient: & t: 2014 dollars \\
\hline Full contact sports & & $\begin{array}{l}\text { Average } \\
(\$)\end{array}$ & Sum (\$) \\
\hline Basketball & 364 & 5931 & 2093583 \\
\hline Boxing & 7 & 4678 & 32746 \\
\hline American football & 852 & 5859 & 4892582 \\
\hline Lacrosse/Field hockey & 22 & 5784 & 115685 \\
\hline Martial arts & 23 & 5423 & 124737 \\
\hline Rugby & 6 & 4017 & 24106 \\
\hline Soccer & 314 & 5502 & 1639706 \\
\hline Wrestling & 95 & 7938 & 738274 \\
\hline \multicolumn{4}{|l|}{ Limited contact sports } \\
\hline Baseball & 230 & 5063 & 1139159 \\
\hline Bike riding & 249 & 7908 & 1921557 \\
\hline Flag football & 46 & 5957 & 268087 \\
\hline Frisbee & 3 & 28366 & 85099 \\
\hline Horseback riding & 63 & 6227 & 386081 \\
\hline Racquet/Hand sports & 4 & 6203 & 24812 \\
\hline Roller-skating/Skateboarding & 258 & 5592 & 1425874 \\
\hline School games & 37 & 4745 & 166081 \\
\hline Volleyball & 20 & 12370 & 321621 \\
\hline \multicolumn{4}{|l|}{ Non-contact sports } \\
\hline Bowling & 3 & 4788 & 14363 \\
\hline Golf & 16 & 14693 & 235090 \\
\hline Jumping rope & 2 & 3231 & 6462 \\
\hline $\begin{array}{l}\text { Non-running track and field } \\
\text { events }\end{array}$ & 6 & 6633 & 33165 \\
\hline \multicolumn{4}{|l|}{ Other } \\
\hline $\begin{array}{l}\text { Other sports played } \\
\text { individually }\end{array}$ & 245 & 6843 & 1608155 \\
\hline Other sports played as a team & 64 & 5028 & 321792 \\
\hline Other sports & 108 & 8844 & 928664 \\
\hline \multicolumn{4}{|l|}{ Mechanism } \\
\hline Fall from sports & 353 & 6470 & 2245043 \\
\hline Struck in sports & 1383 & 5431 & 7365263 \\
\hline Struck in sports with fall & 516 & 6177 & 3131919 \\
\hline
\end{tabular}

E-code, external cause of injury code.

elementary school were $27.4 \%$ less while middle school youth were $19.6 \%$ less compared with high school-aged youth. Females were found to have $10.0 \%$ lower costs than males. Elective and trauma admission were associated with $29.8 \%$ and $41.5 \%$ higher costs, respectively, compared with emergency admissions to the hospital. Increased ICISS, indicating lower severity, was associated with a $3.7 \%$ decrease in cost per ICISS unit. Non-contact sports had $57.9 \%$ higher costs per patient compared with contact sports.
Table 4 Financial costs for ED youth by sport E-code, 2010-2014

\begin{tabular}{|c|c|c|c|}
\hline \multirow[b]{2}{*}{ Full contact sports } & \multirow[t]{2}{*}{ Count } & \multicolumn{2}{|c|}{ ED: 2014 dollars } \\
\hline & & $\begin{array}{l}\text { Average } \\
(\$)\end{array}$ & Sum (\$) \\
\hline Basketball & 42682 & 223 & 8089247 \\
\hline Boxing & 533 & 247 & 111090 \\
\hline American football & 53035 & 255 & 11517088 \\
\hline Lacrosse/Field hockey & 1839 & 283 & 377553 \\
\hline Martial arts & 2253 & 242 & 466115 \\
\hline Rugby & 252 & 318 & 64611 \\
\hline Soccer & 19458 & 248 & 3994243 \\
\hline Wrestling & 5078 & 273 & 1137725 \\
\hline \multicolumn{4}{|l|}{ Limited contact sports } \\
\hline Baseball & 16421 & 246 & 3340503 \\
\hline Bike riding & 9806 & 337 & 2814189 \\
\hline Flag football & 2310 & 269 & 524042 \\
\hline Frisbee & 182 & 201 & 31705 \\
\hline Horseback riding & 1088 & 444 & 403776 \\
\hline Racquet/Hand sports & 539 & 244 & 108044 \\
\hline $\begin{array}{l}\text { Roller-skating/ } \\
\text { Skateboarding }\end{array}$ & 11518 & 319 & 3027545 \\
\hline School games & 2398 & 237 & 479858 \\
\hline Volleyball & 3894 & 224 & 690352 \\
\hline \multicolumn{4}{|l|}{ Non-contact sports } \\
\hline Bowling & 281 & 189 & 44228 \\
\hline Golf & 346 & 628 & 160109 \\
\hline Jumping rope & 252 & 193 & 42413 \\
\hline $\begin{array}{l}\text { Non-running track and } \\
\text { field events }\end{array}$ & 136 & 218 & 25947 \\
\hline \multicolumn{4}{|l|}{ Other } \\
\hline $\begin{array}{l}\text { Other sports played } \\
\text { individually }\end{array}$ & 2746 & 283 & 707440 \\
\hline $\begin{array}{l}\text { Other sports played as } \\
\text { a team }\end{array}$ & 2557 & 238 & 529666 \\
\hline Other sports & 1539 & 303 & 424139 \\
\hline \multicolumn{4}{|l|}{ Mechanism } \\
\hline Fall from sports & 7479 & 599 & 3497997 \\
\hline Struck in sports & 100846 & 655 & 55315947 \\
\hline Struck in sports with fall & 13967 & 315 & 3785643 \\
\hline
\end{tabular}

\section{DISCUSSION}

Sports injuries to Florida youth aged 5-18 are associated with significant expense, totalling \$112 million from 2010 to 2014 . Annually, this equates to $\$ 22.3$ million in healthcare costs in Florida alone and that is just for hospital care. The cost of all sports injuries for youth patients would probably be much higher if primary care, urgent care and specialist visits were included. High school-aged youth and males were two key groups that consistently 
Table 5 Regression model of cost of inpatient youth injured in sport

\begin{tabular}{|c|c|c|c|c|}
\hline & & Parameter estimate & $P$ value & Percentage change to cost (\%) \\
\hline \multirow[t]{14}{*}{ Patient factors } & Elementary school ${ }^{\star}$ & -0.320 & $<0.0001$ & -27.4 \\
\hline & Middle school $^{\star}$ & -0.218 & $<0.0001$ & -19.6 \\
\hline & Female $^{\star}$ & -0.105 & $<0.0001$ & -10.0 \\
\hline & Black & 0.046 & 0.2644 & \\
\hline & Other race & -0.000 & 0.9945 & \\
\hline & Hispanic & 0.030 & 0.4760 & \\
\hline & Uninsured & 0.025 & 0.7049 & \\
\hline & Medicaid & 0.047 & 0.1605 & \\
\hline & Full contact sports & 0.003 & 0.9352 & \\
\hline & Non-contact sports ${ }^{\star}$ & 0.457 & 0.0030 & 57.9 \\
\hline & Elective admission ${ }^{\star}$ & 0.261 & $<0.0001$ & 29.8 \\
\hline & Urgent admission & -0.113 & 0.0850 & \\
\hline & Trauma admission* & 0.347 & $<0.0001$ & 41.5 \\
\hline & ICISS $^{*}$ & -0.038 & $<0.0001$ & -3.7 \\
\hline \multirow[t]{6}{*}{ Nature of injury } & Fractures of the skull, neck or trunk & -0.048 & 0.6197 & \\
\hline & Other fractures* & 0.309 & 0.0004 & 36.2 \\
\hline & Internal injury* & -0.526 & $<0.0001$ & -40.9 \\
\hline & Dislocation & -0.086 & 0.5254 & \\
\hline & Open wound & 0.105 & 0.4708 & \\
\hline & Other injury & -0.203 & 0.1435 & \\
\hline \multirow[t]{4}{*}{ Hospital factors } & Rural hospital & 0.338 & 0.2551 & \\
\hline & Teaching hospital* & 0.067 & 0.0685 & \\
\hline & For profit hospital & -0.026 & 0.5343 & \\
\hline & Government hospital ${ }^{\star}$ & 0.122 & 0.0221 & 13.0 \\
\hline
\end{tabular}

The values in bold indicate statistical significance at the $\alpha=0.05$ level.

*Statistically significant at the $\alpha=0.05$ level.

ICD-9, International Classification of Diseases, Ninth Revision; ICISS, ICD-9 Injury Severity Score.

had higher cost of sports injuries. Considering volume, sports to target for prevention programme include baseball, basketball, bike riding, American football, roller-skating/skateboarding and soccer, as each of these had the highest inpatient and ED costs over the 5-year time period studied. Youth covered by Medicaid insurance had the highest average cost for inpatient visits, indicating substantial costs to taxpayers stemming from sports injuries.

An unexpected result from this analysis was the impact of non-contact sports injuries on youth, such as injuries from bowling, golf, jumping rope, and non-running track and field events. Contact sports such as American football and soccer receive much more attention in the media as well as in scientific studies. Based on the literature review, the non-contact sports group was not expected to have severe injuries let alone statistically significant higher cost from their injuries when compared with a contact sports group. After reviewing the non-contact sports group observations, there were only 27 observations but they included severe and serious injuries. Further research is needed to determine how these injuries occurred.
This may provide guidance in developing prevention programmes for youth athletes in non-contact sports.

Preventive policies and programmes for sports injury have usually been focused on a particular sport or at a local level. For instance, US soccer recently banned heading for youth in U-11 programmes and younger. American football rules have also changed over the last several decades to prevent injury; for example, spearing was banned in 1976 through 'recent return to play laws'. ${ }^{23}$ These are examples of steps that can reduce injuries and healthcare costs. More recently, policies enacted in all 50 states educate youth athletes, parents and coaches on the signs and symptoms of concussion. These policies appear to be effective as demonstrated by increases in diagnosis of concussion in EDs. ${ }^{245}$ However, these policies are only preventive in reducing subsequent injury after an initial harmful event. Policies that prevent injury in sports could potentially save youth athletes from pain and save families, insurance companies and the government from unnecessary healthcare spending.

There are limitations to this study. The analysed data were from AHCA's ED, inpatient and financial data 
sets. These administrative data sets come with three inherent limitations: (1) they reflect the number of visits as opposed to the number of patients; (2) comprehensiveness of reporting depends on the availability of field space (eg, a limit of three injury mechanisms), which may result in potential under-reporting; and (3) clinical findings are not reported. ${ }^{26}$ Furthermore, the data sets do not allow tracking of a patient over time. Any hospital transfer, readmission or follow-up visit would be entered as a new patient record, which is why the data set reflects counts of injury visits and not counts of injuries. E-codes have been estimated to be missing $30 \%$ of the time, ${ }^{27}$ which is why sports injury and injury mechanism may be under-reported. After adjusting for under-reporting, sports injuries rose from $13.9 \%$ to $20 \%$ of hospitalisations. Their analysis estimated an additional 6\%-22.9\% of hospital injuries may be sports-related but not reported as such. Consequently, healthcare costs associated with youth sports injuries in the present analysis may be under-reported.

Finally, the AHCA ED data did not fit the financial cost model well; the results were not consistent, making inferences difficult. The lack of consistency in this model may be explained by the nature of the financial measurements reported by individual hospitals and by the small range of some of the variables combined with the sheer size of the data set. It is possible that additional data on the patient and their sports injury could build a more reliable model, such as height, weight, arrival by ambulance and acute versus chronic injury.

Sports are a meaningful way to exercise, maintain health, release stress and build confidence and friendships among youth. The goal is for youth to continue playing sports while lowering the risk of injury, especially as Frisch $e t a l^{1}$ found the most consistent risk factor for injury is having a previous injury. ${ }^{1}$ Lowering the risk of sports injury would save the health of youth athletes and significant healthcare costs annually. Marshall et al found that one prevention programme aimed solely at youth soccer could save millions of dollars in healthcare costs annually. ${ }^{28}$

Future research is needed to identify and assess which prevention programmes are effective among sports and athlete groups in creating cost and time savings. Translational research is needed to find prevention programmes and policies that can be instituted at a broad level for athletes in full contact, limited contact and non-contact sports.

Contributors JLR, BLO and EEP all substantially contributed to the conception of the work and analysis of data. JLR drafted the work, and BLO and EEP critically revised it. All authors approved the final submission and agree to be accountable.

Funding The authors have not declared a specific grant for this research from any funding agency in the public, commercial or not-for-profit sectors.

Competing interests None declared.

Patient consent for publication Not required.

Ethics approval The data sets are de-identified and publicly available, making this research exempt from an institutional review board review.

Provenance and peer review Not commissioned; internally peer reviewed.
Open access This is an open access article distributed in accordance with the Creative Commons Attribution Non Commercial (CC BY-NC 4.0) license, which permits others to distribute, remix, adapt, build upon this work non-commercially, and license their derivative works on different terms, provided the original work is properly cited, appropriate credit is given, any changes made indicated, and the use is non-commercial. See: http://creativecommons.org/licenses/by-nc/4.0/.

\section{REFERENCES}

1. Frisch A, Croisier J-L, Urhausen A, et al. Injuries, risk factors and prevention initiatives in youth sport. Br Med Bull 2009;92:95-121.

2. Khan KM, Thompson AM, Blair SN, et al. Sport and exercise as contributors to the health of nations. Lancet 2012;380:59-64.

3. Knowles SB, Marshall SW, Miller T, et al. Cost of injuries from a prospective cohort study of North Carolina high school athletes. Inj Prev 2007;13:416-21.

4. Lawrence BA, Spicer RS, Miller TR. A fresh look at the costs of nonfatal consumer product injuries. Inj Prev 2015;0:1-7.

5. Leadbeater B, Babul S, Jansson M, et al. Youth injuries in British Columbia: type, settings, treatment and costs, 2003-2007. Int J Inj Contr Saf Promot 2010;17:119-27.

6. Mitchell J. The case for revolution in school sports. Journal of the Philosophy of Sport 2004;XXXI:64-77.

7. Yang J, Peek-Asa C, Allareddy V, et al. Patient and hospital characteristics associated with length of stay and hospital charges for pediatric sports-related injury hospitalizations in the United States, 2000-2003. Pediatrics 2007;119:e813-20.

8. Centers for Disease Control and Prevention, National Center for Injury Prevention and Control, Division of Unintentional Injury Prevention (CDC). A national Action Plan for child injury prevention: reducing sports and recreation-related injuries in children, 2013. Available: http://www.cdc.gov/safechild/NAP/overviews/sports.html [Accessed 2016].

9. Cumps E, Verhagen E, Annemans L, et al. Injury rate and socioeconomic costs resulting from sports injuries in Flanders: data derived from sports insurance statistics 2003. Br J Sports Med 2008;42:767-72.

10. Finch CF. Getting sports injury prevention on to public health agendas - addressing the shortfalls in current information sources. Br J Sports Med 2012;46:70-4.

11. Finch CF, Wong Shee A, Clapperton A. Time to add a new priority target for child injury prevention? The case for an excess burden associated with sport and exercise injury: population-based study. BMJ Open 2014:4:1-6.

12. Schwebel DC, Brezausek CM. Child development and pediatric sport and recreational injuries by age. J Athl Train 2014;49:780-5

13. Brenner JS, American Academy of Pediatrics Council on Sports Medicine and Fitness. Overuse injuries, overtraining, and burnout in child and adolescent athletes. Pediatrics 2007;119:1242-5.

14. American Academy of Pediatrics (AAP). Medicaid facts, 2017 Available: https://www.aap.org/en-us/Documents/federaladvocacy_ medicaidfactsheet florida.pdf [Accessed cited 2017].

15. Safe Kids Worldwide. Sports safety policy brief, 2016. Available: https://www.safekids.org/sports-safety-policy-brief [Accessed 2017]

16. Timpka T, Lindqvist K, Ekstrand J, et al. Impact of social standing on sports injury prevention in a WHO safe community: intervention outcome by household employment contract and type of Sport. Br J Sports Med 2005;39:453-7.

17. $\mathrm{Ni} \mathrm{H}$, Barnes P, Hardy AM. Recreational injury and its relation to socioeconomic status among school aged children in the US. Inj Prev 2002;8:60-5.

18. Dekker R, Kingma J, Groothoff JW, et al. Measurement of severity of sports injuries: an epidemiological study. Clin Rehabil 2000;14:651-6.

19. Miller TR, Romano EO, Spicer RS. The cost of childhood unintentional injuries and the value of prevention. Future Child 2000;10:137-63.

20. Webborn N. Lifetime injury prevention: the sport profile model. $\mathrm{Br} \mathrm{J}$ Sports Med 2012;46:193-7.

21. Committee on Sports Medicine and Fitness. Medical conditions affecting sports participation. Pediatrics 2001;107:1205-9.

22. Barell V, Aharonson-Daniel L, Fingerhut $L A$, et al. An introduction to the Barell body region by nature of injury diagnosis matrix. Inj Prev 2002;8:91-6.

23. Kim S, Connaughton DP, Spengler J, et al. Legislative efforts to reduce concussions in youth sports: an analysis of state concussion statutes. Journal of Legal Aspects of Sport 2017;27:162-86.

24. Gibson TB, Herring SA, Kutcher JS, et al. Analyzing the effect of state legislation on health care utilization for children with concussion. JAMA Pediatr 2015;169:163-8. 
25. Mackenzie B, Vivier P, Reinert S, et al. Impact of a state concussion law on pediatric emergency department visits. Pediatr Emerg Care 2015;31:25-30.

26. Florida Department of Health. Florida injury surveillance data system, 2017. Available: http://www.floridahealth.gov/statisticsand-data/florida-injury-surveillance-system/index.html [Accessed 2017].
27. Finch CF, Boufous S. Do inadequacies in ICD-10-AM activity coded data lead to underestimates of the population frequency of sports/ leisure injuries? Inj Prev 2008;14:202-4.

28. Marshall DA, Lopatina E, Lacny S, et al. Economic impact study: neuromuscular training reduces the burden of injuries and costs compared to standard warm-up in youth soccer. Br J Sports Med 2016;50:1388-93. 